\title{
The Rich Get Richer and the Poor Get Robbed: Inequality in U.S. Criminal Victimization, 1974-2000
}

\author{
David Thacher ${ }^{1,2}$
}

\begin{abstract}
This paper investigates inequality in criminal victimization in the United States over the past quarter century. By analyzing data from the National Crime Victimization Survey, it shows that the crime drop since the early 1970s has benefited upper-income households much more than the poor, so that criminal victimization has become more concentrated among the poor (particularly in the area of nonstranger violence). The paper then decomposes this trend statistically in order to investigate factors that may explain it. That analysis finds that demographic changes in each quintile explain a significant share of the growing concentration of criminal victimization among the poor.
\end{abstract}

KEY WORDS: crime victimization; inequality; stratification; demographic change.

\section{INTRODUCTION}

Research about criminal victimization has repeatedly found that the burdens of crime are distributed unequally across different social groups, including race and class. Nearly all of this research has been cross-sectional, aiming to describe and explain variation in victimization risk across social groups at a single point in time; to date, criminologists have not systematically investigated how and why the distribution of victimization across groups has changed over time (Meier and Miethe, 1993, p. 470; but see Levitt, 1999a; Trickett, et al., 1995). In this paper, I will show that this kind of longitudinal analysis reveals a largely unnoticed trend in criminal victimization: Since the 1970s, U.S. criminal victimization has become markedly more concentrated in the poorest economic groups, as the overall drop in crime since 1974 has benefited upper-income households much more than

${ }^{1}$ Gerald R. Ford School of Public Policy and A. Alfred Taubman College of Architecture and Urban Planning, University of Michigan, Ann Arbor, MI.

${ }^{2}$ Public Policy and Urban Planning, University of Michigan, 712 Oakland St, Room 340, Ann Arbor, MI 48104"\# Phone: +1-734-615-4074; E-mail: dthacher@umich.edu. 
it has benefited the poor. By decomposing this trend statistically, I show that a large share of this distributional change has been driven by demographic changes within each economic group.

Longitudinal analysis of this kind is important for a number of reasons. First, the study of trends over time can help to integrate victimization literature with broader sociological concerns about inequality and stratification, which have often focused on the historical growth in social inequality. For example, studies of income inequality (e.g. Levy and Murnane, 1992) and inequalities in health (e.g. Pappas et al., 1993) have often tried to describe and explain the growth of inequality in these spheres over time. An important question, largely neglected by both the victimization literature and the broader literature about social inequality and stratification, is whether the distribution of criminal victimization has reinforced these trends in other areas of social life. Second, when studying the distribution of a social burden like criminal victimization, it is difficult to interpret the significance of a given level inequality without knowing whether it is higher or lower than it was in the past (Wagstaff et al., 1989, pp. 89-90). An equal distribution of crime is almost certainly unattainable (there may even be normative reasons why it is an inappropriate ideal, as discussed below), but large increases in the concentration of crime among the poor are at least prima facie cause for concern. Finally, from a theoretical perspective, it is not generally the case that the factors that influence cross-sectional variation will explain variation over time, so the study of longitudinal trends in victimization inequality represents a distinctive and unexplored topic for theorizing.

It is particularly appropriate to focus on victimization inequality across economic groups because inequality in the distribution of any social burden is of greatest concern when it exacerbates the inequalities that accumulate in other spheres of life (Walzer, 1973; Barr and Pease,1990; Miller, 1995). ${ }^{3}$

\footnotetext{
${ }^{3}$ In general, victimization research has not focused directly on inequality across economic groups because its goal only indirectly involves distribution. For example, routine activities theorists investigate the distribution of victimization across social groups not because it is thought to be important in itself but in order to identify factors that drive overall levels of crime in society (Cohen and Felson, 1979). Consequently, this research has investigated distribution across social groups defined by characteristics thought to be most important in affecting the risk of crime rather than characteristics that are thought to be normatively significant in themselves (i.e. those that reflect important axes that separate the advantaged from the disadvantaged). In practice, of course, there is much overlap between these two principles for the definition of social groups. The point is simply that because of its specific (and entirely appropriate) scholarly goals, routine activities research has not systematically focused on the question of whether inequalities in the distribution of crime exacerbate inequalities of other origins. Similarly, Trickett, et al. (1995) study of how the geographic distribution of crime victimization in Britain changed during the 1980s was designed to address important issues in the literature about geography and crime rather than the normative issues discussed in the text.
} 
Indeed, research about disparities in victimization risk across race and ethnicity - another important axis that separates the advantaged from the disadvantaged in the U.S. - has generated significant interest, as scholars have found that people of color are much more likely to be victimized by crime than whites (though longitudinal trends in this disparity have not been studied in detail) (e.g. DiIulio, 1989; Sampson and Lauritsen, 1997; Lauritsen and White, 2001). Moreover, the broader literature on social stratification (e.g. the research about health inequality already cited) has invariably focused on economic and racial disparities in social benefits and burdens. Because these kinds of inequalities would have special normative significance, it is especially important to determine whether they are growing. This paper focuses on inequality across income groups because income is the most direct axis that separates the advantaged from the disadvantaged.

\section{PREVIOUS RESEARCH ON VICTIMIZATION INEQUALITY}

Although criminologists have not studied longitudinal trends in victimization inequality, economist Levitt (1999a) recently examined this issue in a provocative study that seems to have escaped notice in criminology. By analyzing National Crime Victimization Survey (NCVS) data, Levitt found that although the distribution of violent crime across economic groups has not changed over time, property crime became more concentrated among the poor from 1974 to 1993. Levitt's study suggests that the distribution of victimization may be shifting towards the poor, albeit only among property crimes, which are generally less serious than violent crimes.

Levitt's important study can be extended in two ways. First, in his analysis of NCVS data, Levitt did not account for the 1992 redesign of the survey. As described elsewhere (Kindermann, et al.,1997), the redesigned survey uncovered more victimization for almost every social group, and the increase tended to be greater for those with higher incomes than those with lower incomes. Consequently, any effort to compare pre-1992 data with post-1992 data (Levitt compared 1974-1975 data with 1993-1994 data) must account for the effects of the redesign. While Levitt's paper raises a significant and previously neglected question, its findings may not be valid.

Second, although Levitt's exploratory paper discussed possible explanations for the trends he identified (Levitt, 1999a, pp. 87, 91), it did not test those explanations directly, so that issue stands out as an important issue for new research. The limited nature of available data makes it difficult to test many of the most plausible explanations for changes in victimization inequality directly, but it is possible to investigate one simple but important hypothesis: That victimization inequality may change in response to differential socioeconomic changes across different economic groups. (For 
simplicity, I will focus on income quintiles as the relevant economic groups.) Since previous research associated with lifestyle and routine activities theories has shown that victimization risk tends to vary with certain demographic characteristics (notably age, gender, marital status, residential location, and income itself) (Meier and Miethe, 1993, pp. 466-470), differing demographic trends across different income quintiles could cause victimization inequality to vary. For example, if demographic groups with high risks of victimization (e.g. the young) became more concentrated among the poor over time, that change could cause victimization inequality to grow. Similar hypotheses have played a role in other areas of criminology. For example, differences in demographic composition have been used to help explain cross-sectional differences in victimization among racial and ethnic groups (Lauritsen and White, 2001), and longitudinal research about trends in the level of crime in the U.S. has investigated the extent to which changes in the age structure of the population can explain changes in the crime rate (e.g. Levitt, 1999b). Here, I propose to investigate an analogous hypothesis that I will refer to as "the demographic change hypothesis": that changes in the demographic structure of different income quintiles can explain changes in victimization inequality. This hypothesis can be stated more precisely by decomposing changes in the quintile-specific victimization rates into two components: (1) The portion due to changes in the demographic composition of each quintile (i.e. holding the victimization rate for each demographic group constant), and (2) the portion due to changes in the victimization rate of each demographic group within the quintiles. ${ }^{4}$ The demographic change hypoth-

${ }^{4}$ More formally, any quintile victimization rate can be written as the sum of two or more group-specific rates within the quintile, each weighted by the proportion of the quintile that is in that group (e.g. $V=V_{\text {male }} \cdot P_{\text {male }}+V_{\text {female }} \cdot P_{\text {female }}$, where $V$ represents the victimization rate and $P$ the proportion of the quintile's population). A change in the overall quintile victimization rate from 1975 to 1994 could then be written as the weighted average of the gender-specific rates:

which can be manipulated to yield

$$
\begin{aligned}
\Delta V=V^{1994}-V^{1975}= & \left(V_{\text {male }}^{1994} \cdot P_{\text {male }}^{1994}+V_{\text {female }}^{1994} \cdot P_{\text {female }}^{1994}\right) \\
& -\left(V_{\text {male }}^{1975} \cdot P_{\text {male }}^{1975}+V_{\text {female }}^{1975} \cdot P_{\text {female }}^{1975}\right)
\end{aligned}
$$

$$
\begin{aligned}
& {\left[\left(P_{\text {male }}^{1994}-P_{\text {male }}^{1975}\right) \cdot V_{\text {male }}^{1994}+\left(P_{\text {female }}^{1994}-P_{\text {female }}^{1975}\right) \cdot V_{\text {female }}^{1994}\right]} \\
& \quad+\left[P_{\text {male }}^{1975} \cdot\left(V_{\text {male }}^{1994}-V_{\text {male }}^{1975}\right)+P_{\text {female }}^{1975} \cdot\left(V_{\text {female }}^{1994}-V_{\text {female }}^{11755}\right)\right]
\end{aligned}
$$

since expanding products and canceling terms recovers the original expression. The bracketed expressions correspond to the decompositions described in the text: The left-hand expression is the portion of the overall change in the victimization rate due to the changing demographic composition of the quintile, while the right-hand expression is the portion due to the change in group-specific rates (i.e., the change that would have occurred if the composition had remained constant). The overall change can also be decomposed in a slightly different way, using 1975's group-specific rates rather than 1994's to calculate the share due to compositional changes and using 1994's compositional data rather than 1975's to calculate the share due to changes in the group-specific victimization rates. In my analyses, however, the two decompositions give similar results, so I will not present results from the latter decomposition. 
esis predicts that a large share of any change in victimization inequality will be due to the first portion of the decomposition.

This potential explanation for trends in victimization inequality is admittedly not a sociologically deep one: It holds that compositional changes, rather than any subtle economic or sociological processes, drive changes in victimization inequality. Nevertheless, it represents an important possibility in the study of social inequality. Since changes in victimization inequality have prima facie normative significance for the reasons explained in the introduction, it would be important to know that those changes have their sources in demographic changes (rather than, say, the increasing ability of the wealthy to afford luxuries of self-protection like security devices and homes in safe neighborhoods - a possibility noted by Levitt ( 1999a, pp. 87, 91). It would be too simple to say that this finding would mean that observed changes in victimization inequality have no normative significance at all. For example, if changes in marital status composition explained growth in victimization inequality and the decline of marriage among the poor is a consequence of their worsening economic situation (Wilson, 1987), then the growth of victimization inequality would be an unfortunate byproduct of broader patterns of social stratification, and therefore another reason to be concerned about those patterns. Nevertheless, a discovery that demographic composition explains changes in victimization inequality would cast the normative issues raised by victimization inequality in a particular light, as discussed further in the conclusion.

Apart from its intrinsic importance, a preliminary analysis of the demographic change hypothesis can also lay the groundwork for future studies that explore more complex social processes. If income-specific demographic changes influence victimization inequality, the next question becomes how they do so - what causal processes mediate the relationship between the demographic composition of different income groups and victimization inequality.

\section{DATA AND METHODS}

To explore these issues, this study investigates two questions: whether the distribution of different kinds of criminal victimization across income groups has changed in the U.S. since the early 1970s (Section 4), and whether demographic shifts in the population have contributed to those changes by concentrating high-risk groups in lower economic strata (Section 5). The study relies on computerized data from the (NCVS) and its predecessor, the National Crime Survey (NCS), which have been described in detail elsewhere (U.S. Dept. of Justice, 1998-1999), and it also draws on published reports of those data (U.S. Dept. of Justice, 1974-2000). The 
crime surveys rely on interviews with a stratified, multi-stage cluster sample of U.S. residents using a rotating panel design. Sample size has fluctuated somewhat since the inception of the NCS, but in 2000, 86,800 households and 159,420 individuals age 12 or older were interviewed, and the response rate was $93.4 \%$ of eligible households and $89.6 \%$ of eligible individuals (Rennison, 2001).

The study focuses on violent crimes (including assaults, robberies, and rapes), thefts (including household thefts and motor vehicle thefts), and burglaries. Thefts and burglaries are analyzed separately because the nature of inequality for each type of crime is very different. While burglaries (like violent crimes) are concentrated disproportionately among the poor, household thefts and motor vehicle thefts are concentrated disproportionately among the wealthy (though to a lesser extent than 25 years ago). Most of the discussion will focus on violent crimes because violence is the most significant aspect of America's crime problem (Zimring and Hawkins, 1997, pp. 1-11 and passim), making inequality in its distribution particularly important. In addition to the overall violent crime rates, I will also examine rates for nonstranger violence and stranger violence separately.

To assess how the distribution of crime across income groups has changed over time, I have used published NCVS and NCS data that describe victimization rates for different income groups from 1974 to 2000 to compute various measures of inequality that compare criminal victimization across income groups - i.e. groups defined by their degree of social advantage as discussed above. The most important ratio I will use is the " $20-20$ " ratio, defined as the victimization rate for individuals in the poorest $20 \%$ of households divided by the rate for individuals in the wealthiest $20 \%$ of households. ${ }^{5}$ (In 2000, the 20th percentile household earned $\$ 17,950$ and the 80th percentile household earned $\$ 81,960$.) Like all scalar summaries of two-dimensional distributions, this one obviously has weaknesses, such as the fact that it is insensitive to changes in victimization at the middle of the income distribution. But it has the advantages of simplicity and intuitive interpretation, and a similar approach has been used commonly in studies of income distribution (e.g. Lerman, 1997). In any case, I will show that more sophisticated (though also more opaque) measures of inequality suggest the same patterns as the 20-20 ratio does. In particular, I will use a measure of

\footnotetext{
${ }^{5}$ This method of analyzing inequality differs from Levitt's (1999a), which focused on the victimization rate of groups defined by inflation-adjusted income ranges. For a variety of reasons, it is more conventional in the literatures about health and income inequality to focus on quintiles rather than fixed income ranges, so I emphasize that approach here.
} 
inequality called the concentration index (CI), which is conceptually similar to the Gini coefficient and has been used extensively by health economists to measure inequality in health across economic groups (Kakwani, et al., 1997). As used here, the CI varies from - 1.0 to 1.0, and as it becomes larger and more positive, it indicates a higher concentration of victimization among low-income groups; a CI of zero indicates that every income group is victimized at the same rate.

The crime surveys make it possible to use these methods to describe victimization inequality, but only approximately. The surveys do not ask respondents for exact household incomes. Instead, interviewers ask which range a household's income falls into (e.g. \$7,500-\$9,999), so it is not possible to identify precisely those households that lie above or below a particular percentile; some income groups will fall entirely above or below the percentile, but one group will inevitably straddle it. Here, in order to estimate the victimization rate for households whose income falls below a given percentile (as reported in the annual Current Population Survey conducted by the Census Bureau), I will interpolate the contribution of the group that straddles the percentile. (Details are available from the author.) Similarly, the lack of precise income data means that the CI must also be approximated, as is often done in the study of other forms of inequality (Kakwani, et al., 1997, p. 89). These methods for calculating measures of inequality are unavoidably imprecise, but since I will show that a variety of different measures converge on the same basic picture of inequality, it is unlikely that the trends I present result from interpolation errors.

As I will show, these analyses show that several types of victimization have become much more concentrated among the poor over the past 25 years. To investigate whether and how income-specific demographic changes explain those trends, I decompose them according to several demographic variables and ask, counterfactually, how victimization inequality would have changed if the demographic composition of each income group had not. I explain this methodology in more detail (Section 5) after establishing the nature of the trends in inequality.

\section{CHANGES IN VICTIMIZATION INEQUALITY, 1974-2000}

Using the methods just described, Fig. 1 and Table I show how the distribution of criminal victimization across income groups has changed from 1974 to 2000 . These data show that all categories of crime have become more concentrated among the poorest $20 \%$ of households. For violent crimes, the 20-20 ratio grew from 1.15 during the 1974-1980 
period to 1.76 in the 1994-2000 period (a 53\% increase). For burglary, the 20-20 ratio followed the violent crime changes closely, growing from an average of 1.12 during the $1974-1980$ period to 1.75 during the 19942000 period (a 56\% increase). For household theft and motor vehicle theft, the 20-20 grew by the same factor from a lower base, from an average of 0.49 during the 1974-1980 period to 0.76 during the 1994-2000 period (a 55\% increase). These findings contrast with Levitt's (1999a) conclusion that only property crime has become more concentrated among the poor. Once the effects of the survey redesign have been accounted for (in ways I will describe shortly), it appears that all crimes have become more concentrated among the poor.

Different measures of inequality offer the same picture as the 20-20 ratio. As shown in Table I, the CI follows the 20-20 ratio closely. For violent crimes, the CI grew from an average of 0.130 in the 1974-1980 period to an average of 0.215 in the 1994-2000 period. For burglary, the CI grew from 0.065 to 0.251 during the same period, and the CI for household theft and motor vehicle theft fell from -0.381 to -0.109 - that is, theft victimization became more equal by becoming more concentrated among the poor than it was in the 1970s. Other measures of inequality (not shown in Table I) offer further confirmation of these patterns: From the 1974-1980 period to the 1994-2000 period, the average 40-40 ratio (which refers to the top and bottom $40 \%$ of households) grew from 1.17 to 1.42 for violent crimes, from 1.12 to 1.55 for burglaries, and from 0.57 to 0.82 for thefts. Finally, the $10-10$ ratio (defined similarly) grew from 1.36 to 2.05 for violent crimes, from 1.13 to 1.91 for burglaries, and from 0.51 to 0.76 for thefts between the same two periods. Thus the changes in inequality are not an artifact of a particular measurement procedure but are robust across many different measures of inequality. Moreover, the generally slower growth of the 40-40 ratio compared with the 20-20 and 10-10 ratios is consistent with the idea that the risk of victimization has become more polarized by income, with a greater gap separating the poorest from the wealthiest.

Although the concentration of victimization among low-income groups has grown markedly, even at the end of this period the poor are not dramatically more likely than the rich to be victimized by the crimes reported in the NCVS. For violent crimes, the poorest quintile was about twice as likely to suffer violent crime victimization as the richest quintile in 2000 (20-20 ratio of 1.92), and the disparity for burglaries was comparable. For household thefts and motor vehicle thefts, the poor were less likely to be victimized than the rich for household larcenies in 2000 (20-20 ratio of 0.84), though the gap has closed considerably since the 1970s. It is important to note, however, that the crime surveys uncover many crimes that are relatively trivial, and an examination of more serious crimes reveals a different picture. Consider the 


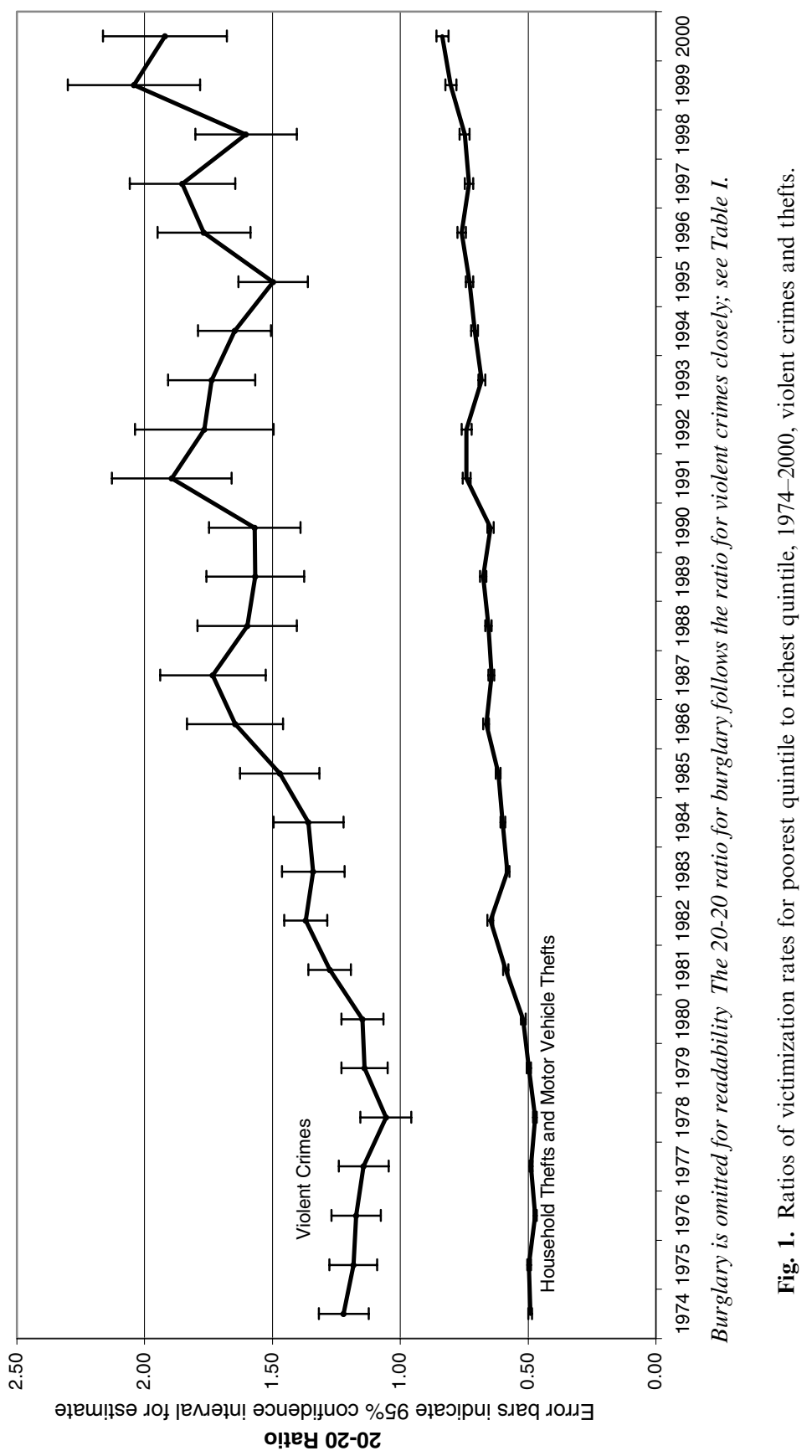




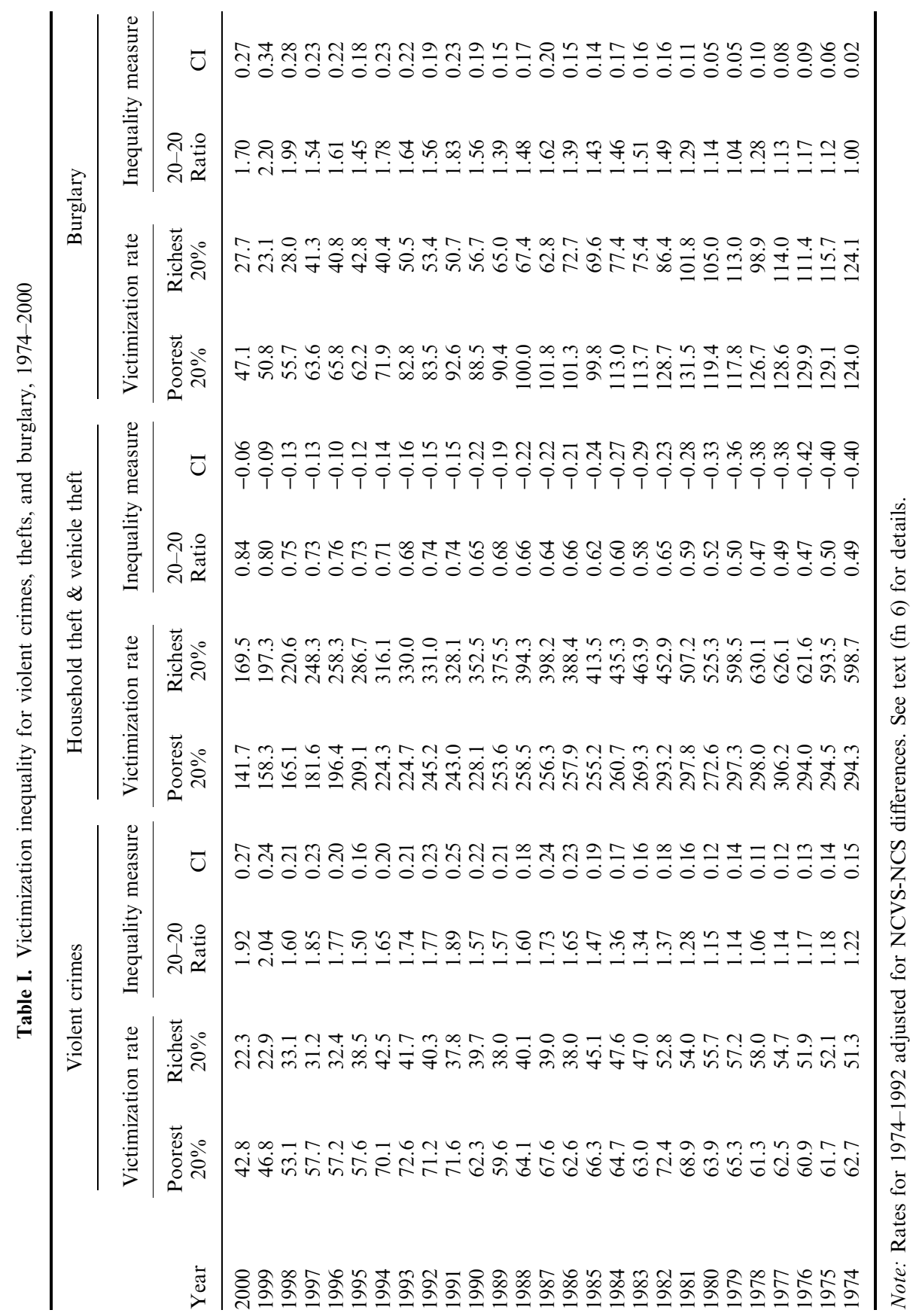


patterns for "serious violent crimes" as defined by the Bureau of Justice Statistics (Hart and Rennison, 2003), including rape, robbery, and aggravated assault. Adjusted for effects of the redesign, the 20-20 ratio for serious violent crimes rose from an average of 1.59 during the 1974-1980 period to 2.54 during the $1994-2000$ period, a $60 \%$ increase. During the same period, the 20-20 ratio for all violent crimes-including less-serious simple assaults - grew from 1.15 to 1.76 , a $53 \%$ increase. Thus the risk premium associated with being poor is twice as large for serious violent crimes as it is for all violent crimes (154\% vs. $76 \%$ ), and it has grown at a slightly faster pace. The disparities are especially large at the end of the period: The 20-20 ratio for serious violence reached 3.09 in 1999 and 2.71 in 2000 (up from 1.56 in 1974). In sum, although the poor are not dramatically more likely to be victimized than the rich for all NCVS crimes, that finding is partly an artifact of the kinds of (relatively nonserious) crimes reported in the NCVS.

The most important source of uncertainty in these trends is the 1992 redesign of the NCS discussed earlier. Table I accounts for the redesign by deflating pre-1993 victimization rates by a fixed percentage for each income quintile, following essentially the same procedure used in published BJS reports, and finding similar patterns in the overall level of crime (e.g. Rand, et al., 1997). ${ }^{6}$ This adjustment reflects the best research that has been done about the differences between the two surveys, but it may not be entirely valid, and the small victimization ratios for burglary and violence in the 1970s and 1980 s could be an artifact of it. Nevertheless, further analysis suggests that the apparent trends in inequality shown in Table I reflect real changes in the distribution of crime, not changes in the crime surveys' methodology. First, the same trends are visible if one only looks at unadjusted data before the redesign, from 1974 to 1992. For example, for violent crime victimization, the unadjusted 20-20 ratio averaged 1.57 from 1974 to 1979 , but from 1987 to 1992 it averaged 2.29 - a 46\% increase. (In this connection, note that because I apply the same factors to all pre-1993 data, trends during those early years are not affected by my adjustments. In other words, trends within the 1974-1992 time series and within the 1993-2000 time series are both unaffected by my

${ }^{6}$ The 1992 survey split the national sample in two, using the old survey on half and the new survey on the other half. Kindermann et al. (1997) analyzed these data to estimate ratios that capture the difference between the two surveys for various demographic groups, including income groups. To make the pre-1993 survey results comparable to more recent surveys, I applied these ratios to the NCS-reported income groups in 1992 and then calculated how much this adjustment inflated the rates for each income quintile in that year, deriving scaling factors for each quintile that would make pre-1993 data comparable to recent data. My analysis also accounts for the different ways in which the NCS and the NCVS treated thefts. Until 1992, larceny/thefts could be classified as either crimes against individuals or as crimes against households, but after that time they were mostly treated as crimes against households. For the earlier years, I have recomputed larceny/thefts against individuals as household thefts. 
adjustments; the adjustments simply make the earlier time series comparable to the later one. Since the trends in both series are generally upward, it is clear that inequality has grown.) Second, the trend also does not change for more serious crimes, as noted in the previous paragraph. In general, changes in survey methodology (including the wholesale redesign in 1992 and less substantial changes such as greater use of telephone reports over time) have larger effects on reports of minor crimes than on reports of serious crimes (Kindermann, et al., 1997, p. 2). If changes in survey methodology caused the apparent changes in victimization inequality described here, then inequality would change more slowly (or not at all) among more serious crimes. In fact, the opposite happened - inequality grew more rapidly for serious violent crimes. Victimization inequality also grew more rapidly for violent crimes reported to police, another subset of crimes that was not affected as strongly by the redesign (Kindermann, et al., 1997, p. 2). For example, from 1975 to 2000, the 20-20 ratio for violent crimes reported to the police (not shown in Table I) grew from 1.30 to 2.46 , a $90 \%$ increase; during the same period, the 20-20 ratio for all violent crimes rose from 1.18 to 1.92 , a $63 \%$ increase. Thus victimization inequality grew more rapidly and reached a higher level for crimes reported to the police. As with the trends for serious violence, that is the opposite of what would be expected if the trends shown in Table I resulted from changes in survey methodology rather than real trends in inequality.

Finally, sampling error also cannot explain the apparent growth in inequality. The 20-20 ratios presented in Table I are estimates based on sample data, so they may not capture the true value of the 20-20 at any point in time. Nevertheless, the $95 \%$ confidence intervals on Fig. 1 show that every estimated 20-20 ratio during the 1990s is statistically different from every 20-20 during the 1970s at the 0.05 level. ${ }^{7}$ Moreover, this kind of

${ }^{7}$ I calculated pointwise confidence intervals and standard errors for the 20-20 ratios in three steps. First, I estimated standard errors for the quintile-specific victimization rates using the generalized variance procedure developed for the crime surveys by the Bureau of Justice Statistics (U.S. Dept. of Justice, 1999). Second, for each type of crime, I generated estimates of the correlation of the quintiles using their empirical correlation over time. Finally, using the estimated quintile variances and their estimated correlation, I estimated the standard error for each ratio with a parametric bootstrap using 100,000 repetitions under the assumption of joint normality (Johnston and DiNardo, 1997). I allowed for uncertainty in the estimate of the correlation coefficient by drawing it from its estimated sampling distribution, using the Fisher transformation. Complete data on standard errors is available from the author. I thank John DiNardo for help making these calculations.

Note that because of the survey redesign, year-to-year comparisons of the sort described in the text are not technically valid after 1992; in comparing recent data to older data, the most important source of uncertainty is not the fact that each estimate comes from a random sample but the fact that the survey methodology changed. Nevertheless, the statement in the text holds for pre-redesign data as well. For example, a $T$-test comparing the 1974 20-20 with the 1991 $20-20$ shows that the latter ratio is indeed larger $(p<0.05)$. 
comparison between a single recent year and the average from an earlier decade is extremely conservative as a test of whether the apparent changes in Table I are real rather than a result of sampling error. What needs to be explained is not just why the 1991 ratio (for example) is larger than the ratios during the 1970s, but why there is a consistent upward trend throughout the 1980s. Given the consistent patterns over time - e.g. every estimated 20-20 ratio during the 1990s is larger than every estimated 20-20 ratio during the 1970s-unrepresentative random samples could not have generated the apparent growth in inequality.

\subsection{Stranger Violence and Nonstranger Violence}

The discussion so far reveals similar patterns across all types of crime, in the sense that violent crime, burglary, and theft have all become more concentrated among the poor to a similar extent. But further analysis reveals differences within these broad categories. In particular, victimization inequality has followed different trends for violence committed by strangers compared with violence committed by intimates or acquaintances. (Since victims of property crime rarely see the people who victimized them, this kind if analysis cannot be undertaken for theft or burglary.) Analysis of computerized data from the crime surveys (not shown in Table I) shows that the 20-20 ratio for stranger violence grew only marginally, from 1.01 in 1975 to 1.15 in 2000, while the ratio for violent crimes where the victim knew the offender grew more dramatically, from 1.51 in 1975 to 2.79 in 2000 . These figures indicate that much of the growth in victimization inequality for violent crimes has been concentrated in nonstranger crime.

Here especially the redesign of the victimization survey makes it difficult to interpret these figures. As explained above, I adjusted the NCS data from 1975 using factors derived from Kindermann, et al., (1997), but those factors were designed to adjust income-specific victimization rates for all violent crimes, and here I have applied them to subsets of the data - to nonstranger crimes and to stranger crimes. Although no better procedure is readily available, this approach is not technically valid, so it distorts the analysis to some unknown degree. Once again, one way to investigate the significance of this problem is to look at data for crimes that the redesign did not affect as strongly, such as crimes reported to the police. Doing that confirms the basic conclusion in the previous paragraph. Looking only at unadjusted data for violent crimes reported to the police, the 20-20 ratio for stranger violence fell from 1.26 
to 1.24 between 1975 and 2000 , while the ratio for intimate and acquaintance violence rose from 2.68 to 4.16 .

In sum, although the redesign makes it impossible to estimate the trends for nonstranger and stranger crimes with precision, the general pattern seems clear: Victimization inequality has grown more rapidly for nonstranger violence than stranger violence. In any case, since post-1992 data do not need to be adjusted, the most recent disparities are fairly certain: In 2000, the 20-20 was much larger for nonstranger violence than stranger violence.

\subsection{Income-Specific Trends in Victimization}

Although the growth in victimization inequality is potentially troubling, it is also important to note the positive trends in the group-specific rates. In the long haul, Table I shows that victimization risk has fallen in all quintiles. The growth in inequality has not resulted from growth in victimization among the poor but from especially large drops in victimization among the wealthy. For example, the violent crime victimization rate for the poorest quintile fell from 62.6 per 1,000 during the 1974-1980 period (adjusted for NCS-NCVS differences) to 55.0 per 1,000 during the 1994-2000 period (a drop of 11.6, or 12\%), but the same rate for the richest quintile fell more rapidly, from 54.4 to 31.8 (a drop of 22.6, or $42 \%$ ). (Both changes are statistically significant at the 0.05 level, but see the caution at the end of footnote). ${ }^{7}$ Victimization rates fell three-anda-half times faster for the rich compared with the poor, but they fell for both groups.

\section{CAN DEMOGRAPHIC CHANGE EXPLAIN THE GROWTH OF VICTIMIZATION INEQUALITY?}

Having established the nature of the trends in victimization inequality in the last section, this section investigates whether changing demographics have contributed to those trends in two steps. First, to offer an intuitive basis for my central analysis, I begin with brief bivariate analyses that explore how each of several specific aspects of demographic change contributed to the growth in victimization inequality for violent crime. I then move on to a multivariate analysis that explores the simultaneous effects of all these demographic changes on the trends in victimization inequality for violence, burglary, and theft. 


\subsection{Bivariate Analysis}

To analyze the effect of quintile-specific changes in demographic composition on the trends in victimization inequality, I first used the computerized data from the 1975 and 1994 crime surveys to cross-tabulate victimization by income on the one hand, and age, marital status, employment status, and residential location (urban, rural, or suburban) on the other, since those are some of the major demographic groups that have been found to have high risks of criminal victimization in past research (Meier and Miethe, 1993, pp. 466-470). ${ }^{8}$ Moreover, because income itself is associated with victimization risk, I also tabulated data about quintile-specific income changes between 1975 and 1994. Table II presents the relevant data, focusing on the group-specific victimization rates for each quintile and the demographic composition of each quintile.

Table II shows that demographic changes in the U.S. since 1974 are consistent with the demographic change hypothesis, in that the demographic composition of each quintile did change in directions that would be expected to exacerbate victimization inequality. For example, the percentage of individuals in the poorest quintile who were in the high-risk 15-24 year-old age group fell only slightly from 1975 to 1994 (from $26 \%$ to $24 \%$ of the quintile's population) while the percentage of the richest quintile in that age group fell rapidly (from $21 \%$ to $16 \%$ ). Ceteris paribus, these trends would be expected to cause victimization to fall slightly for the poor and more rapidly for the rich, so victimization would become more concentrated among the poor. Similarly, both the proportion of individuals that lived in urban areas and the proportion that was unmarried grew among the poor while falling among the wealthy, and

\footnotetext{
${ }^{8}$ The analyses omit race as an explanatory variable for a variety of reasons. Most simply, trends in the racial composition of each quintile cannot explain the growing concentration of victimization among the poor because they have moved in the wrong direction: From 1975 to 1994, the proportion of the richest quintile that was black grew slightly (from $4.1 \%$ to $5.0 \%$ ), and the proportion of the poorest quintile that was black fell considerably (from $23.4 \%$ to $17.9 \%$ ). Since blacks are a high-victimization group, these trends would be expected to reduce the concentration of victimization among the poor, not increase it. In any case, if race is included in the multivariate analysis presented later, its coefficient is not statistically significant at the 0.10 level, and the overall model predictions change by less than $5 \%$. It is not surprising that race has little additional explanatory power: Past research has shown that a substantial share of racial disparities in victimization can be explained with the kinds of demographic variables I do include (e.g. Lauritsen and White, 2001).

In these analyses, I chose to analyze 1994 data because that was the most recent year for which the necessary person-level and incident-level extract files were available when I began this research. I chose 1975 as a base year because it begins the 20 -year period that ends in 1994 . In any case, these 2 years seem to be good representatives of their respective decades in the sense that the overall 20-20 ratio for each year lies close to the midpoint for its decade.
} 
Table II. Population composition and victimization rates for richest and poorest quintiles, by age, marital status, employment status, and residential location, 1975 and 1994

\begin{tabular}{|c|c|c|c|c|c|c|c|c|}
\hline & \multicolumn{4}{|c|}{ Population composition } & \multicolumn{4}{|c|}{ Violent crime victimization per 1,000} \\
\hline & \multicolumn{2}{|c|}{ Poorest quintile } & \multicolumn{2}{|c|}{ Richest quintile } & \multicolumn{2}{|c|}{ Poorest quintile } & \multicolumn{2}{|c|}{ Richest quintile } \\
\hline & 1975 & 1994 & 1975 & 1994 & 1975 & 1994 & 1975 & 1994 \\
\hline Aged 15-24 & $26 \%$ & $24 \%$ & $21 \%$ & $16 \%$ & 123.0 & 129.2 & 100.5 & 91.4 \\
\hline Other ages & $74 \%$ & $76 \%$ & $79 \%$ & $84 \%$ & 41.7 & 51.1 & 40.2 & 33.1 \\
\hline Married & $39 \%$ & $30 \%$ & $64 \%$ & $66 \%$ & 36.0 & 35.5 & 30.7 & 21.5 \\
\hline Not married & $60 \%$ & $69 \%$ & $36 \%$ & $34 \%$ & 80.6 & 85.0 & 93.4 & 82.8 \\
\hline Male & $41 \%$ & $43 \%$ & $51 \%$ & $52 \%$ & 85.1 & 78.1 & 73.0 & 52.2 \\
\hline Female & $59 \%$ & $57 \%$ & $49 \%$ & $48 \%$ & 47.7 & 64.0 & 32.3 & 31.3 \\
\hline Working & $34 \%$ & $40 \%$ & $61 \%$ & $74 \%$ & 78.2 & 93.0 & 51.3 & 39.8 \\
\hline Not working & $59 \%$ & $50 \%$ & $26 \%$ & $16 \%$ & 51.2 & 42.6 & 36.3 & 26.2 \\
\hline Urban & $34 \%$ & $38 \%$ & $26 \%$ & $23 \%$ & 90.2 & 82.7 & 67.5 & 48.2 \\
\hline Suburban & $35 \%$ & $31 \%$ & $53 \%$ & $65 \%$ & 67.6 & 89.2 & 50.5 & 37.5 \\
\hline \multirow[t]{4}{*}{ Rural } & $31 \%$ & $31 \%$ & $21 \%$ & $12 \%$ & 28.3 & 35.7 & 41.6 & 56.4 \\
\hline & \multicolumn{4}{|c|}{ Quintile boundaries } & \multicolumn{4}{|c|}{$\begin{array}{l}\text { Ratio of } 80 \text { th percentile income } \\
\text { to } 20 \text { th percentile income }\end{array}$} \\
\hline & \multicolumn{2}{|c|}{20 th $\%$ ile income } & \multicolumn{2}{|c|}{ 80th \%ile income } & & & & \\
\hline & 1975 & 1994 & 1975 & 1994 & \multicolumn{2}{|c|}{1975} & \multicolumn{2}{|c|}{1994} \\
\hline Quintile boundary & $\$ 5,025$ & $\$ 13,426$ & $\$ 20,496$ & $\$ 62,841$ & \multicolumn{2}{|c|}{4.08} & \multicolumn{2}{|c|}{4.68} \\
\hline
\end{tabular}

these changes would also be expected to cause victimization inequality to grow. Finally, between 1975 and 1994 the top quintile's income outpaced inflation dramatically (growing $207 \%$, from $\$ 20,496$ to $\$ 62,841$ ) while the bottom quintile's income grew only slightly faster than inflation (growing $167 \%$, from $\$ 5,025$ to $\$ 13,426$ ). These changes might mean that the poor have become less able relative to the rich to afford the luxuries of selfprotection, such as security devices and homes in safe neighborhoods. Ceteris paribus, that kind of change could also cause victimization to become more concentrated among the poor.

Table III refines these intuitions in two steps. First, in the left panel, the table shows how the victimization rates for each quintile would have changed if specific aspects of its demographic composition had remained constant, assuming that the relationship between demography and victimization risk had changed in the way it actually did (as described in footnote). ${ }^{4}$ Second, in the right panel, it uses those hypothetical rates to calculate how the 20-20 ratios would have changed under those conditions. 
(Though conceptually similar, the income analyses proceed somewhat differently, as explained in a footnote. $)^{9}$

These analyses show that changing demographics explain a respectable but not overwhelming share of the trends in inequality for violent crimes. Some demographic changes were too small to account for much of the growth in the 20-20 ratio. The relative drop in the proportion of the poorest quintile that was female was fairly small, and changes in gender composition account for essentially none of the growth in inequality. Other demographic changes, however, appear to have a stronger connection with the growth in victimization inequality. Most dramatically, the proportion of the poorest quintile that was unmarried grew rapidly while the same proportion declined slightly in the richest quintile, and these changes account for almost a third of the overall growth in inequality. Finally, the fact that the bottom quintile's income increasingly lagged behind that of the rich explains onetenth of the growth in victimization inequality for violence. For brevity, I omit comparable analyses of the trends in inequality for theft and burglary, but those analyses (available from the author) give similar results: Individual changes in demographic composition explain a moderate share of the trends in victimization inequality for all three types of crime.

\subsection{Multivariate Analysis}

These analyses are essentially bivariate, in the sense that each one isolates the contribution of a single type of demographic change to the trends in victimization inequality. In reality, however, these demographic changes are likely to interact with one another to influence quintile-specific victimization rates, so only a multivariate analysis can investigate their joint effects

\footnotetext{
${ }^{9}$ In the counterfactual scenario for the income analysis, I asked what the bottom quintile's victimization rate would have been in 1994 if the 20th percentile income had grown as fast as the 80 th percentile income since 1975 (i.e. by $207 \%$ to $\$ 15,407$, rather than by $167 \%$ to $\$ 13,426$ ), assuming that income-specific risks of victimization remained the same as their actual 1994 values. To calculate this predicted victimization rate under the counterfactual scenario, I returned to the raw data that underlie Table I and recalculated the bottom quintile's victimization rate using the counterfactual 20th percentile income (rather than the actual 20th percentile income, which is what I used to calculate the bottom quintile's victimization rate in 1994 in Table I). Doing that meant weighting the bottom quintile's victimization rate more heavily with the lower victimization rates of somewhat wealthier income groups (i.e. those earning between $\$ 13,426$ and $\$ 15,407$ ). Though it proceeds somewhat differently, this method is analogous to the method used for other quintile-specific demographic changes. (For example, one could "decompose" the bottom quintile's victimization rate into a weighted sum of the rates for two income groups: The group earning less than $\$ 13,426$ and the group earning between $\$ 13,426$ and $\$ 15,407$. In reality, the proportion of the bottom quintile's population in the second group was $0 \%$ in 1994; under the counterfactual scenario, it is not.)
} 
Table III. Decomposition of changes in violent crime victimization rates for richest and poorest quintile, 1975-1994

\begin{tabular}{|c|c|c|c|}
\hline & \multicolumn{2}{|c|}{$\begin{array}{l}\text { Victimization rates, } \\
1994\end{array}$} & \multirow[b]{2}{*}{$\begin{array}{l}\text { 20-20 Ratio } \\
1994\end{array}$} \\
\hline & $\begin{array}{l}\text { Poorest } \\
\text { Quintile }\end{array}$ & $\begin{array}{l}\text { Richest } \\
\text { Quintile }\end{array}$ & \\
\hline $\begin{array}{l}\text { Actual violent crime victimization rate or ratio } \\
\% \text { change from } 1975 \text { value (as shown Table I) }\end{array}$ & $\begin{array}{l}70.1 \\
11 \%\end{array}$ & $\begin{array}{c}42.5 \\
-20 \%\end{array}$ & $\begin{array}{l}1.65 \\
40 \%\end{array}$ \\
\hline $\begin{array}{l}\text { If age composition had not changed }{ }^{\overline{\mathrm{a}}} \\
\% \text { change from } 1975 \text { value } \\
\% \text { of growth due to changes in age composition } \\
\overline{\mathrm{b}}\end{array}$ & $\begin{array}{r}71.5 \\
14 \% \\
-21 \%\end{array}$ & $\begin{array}{c}45.5 \\
-14 \% \\
31 \%\end{array}$ & $\begin{array}{l}1.57 \\
32 \% \\
19 \%\end{array}$ \\
\hline $\begin{array}{l}\text { If marital status composition had not changed } \\
\% \text { change from } 1975 \text { value } \\
\% \text { of growth due to changes in marital status } \\
\text { composition }^{\bar{b}}\end{array}$ & $\begin{array}{r}65.5 \\
4 \% \\
63 \%\end{array}$ & $\begin{array}{c}43.2 \\
-18 \% \\
9 \%\end{array}$ & $\begin{array}{l}1.52 \\
28 \% \\
30 \%\end{array}$ \\
\hline $\begin{array}{l}\text { If gender composition had not changed } \\
\% \text { change from } 1975 \text { value } \\
\% \text { of growth due to changes in gender } \\
\text { composition }^{\bar{b}}\end{array}$ & $\begin{array}{r}69.7 \\
11 \% \\
4 \%\end{array}$ & $\begin{array}{r}41.9 \\
-21 \% \\
-3 \%\end{array}$ & $\begin{array}{l}1.66 \\
40 \% \\
-1 \%\end{array}$ \\
\hline $\begin{array}{l}\text { If employment composition had not changed } \\
\% \text { change from } 1975 \text { value } \\
\% \text { of growth due to changes in employment } \\
\text { composition }^{\bar{b}}\end{array}$ & $\begin{array}{r}64.9 \\
3 \% \\
72 \%\end{array}$ & $\begin{array}{l}42.0 \\
-21 \% \\
-2 \%\end{array}$ & $\begin{array}{l}1.55 \\
30 \% \\
24 \%\end{array}$ \\
\hline $\begin{array}{l}\text { If geographic composition (urban, suburban, rural) } \\
\text { had not changed }\end{array}$ & 70.4 & 44.3 & 1.59 \\
\hline$\%$ change from 1975 value & $12 \%$ & $-16 \%$ & $34 \%$ \\
\hline $\begin{array}{l}\% \text { of growth due to changes in geographic } \\
\text { composition }^{\mathrm{b}}\end{array}$ & $-5 \%$ & $20 \%$ & $15 \%$ \\
\hline $\begin{array}{l}\text { If } 20 \text { th } \% \text { ile income had grown as fast as } 80 \text { th \%ile } \\
\text { income } e^{\bar{c}}\end{array}$ & 68.1 & 42.2 & 1.61 \\
\hline$\%$ change from 1975 value & $8 \%$ & $-20 \%$ & $36 \%$ \\
\hline$\%$ of growth due to changes in relative incomes & $27 \%$ & $0 \%$ & $10 \%$ \\
\hline
\end{tabular}

"Victimization rates "if composition had not changed" were calculated by weighting group-specific victimization rates for 1994 by each group's share of the population in 1975 . Table II contains the relevant data.

b $\%$ of growth due to compositional changes is the actual growth minus the hypothetical (composition-constant) growth, divided by the actual growth. Negative values indicate victimization would have grown more than it actually did if composition had remained constant.

${ }^{\bar{c}}$ See text, footnote 9 for details.

adequately. To investigate the combined contribution of all demographic changes to the trends in victimization inequality, I modeled the relationships between demographic characteristics and victimization risk in 1994 using multivariate models and then used those models to generate another set of 
counterfactual predicted values: estimates of what the quintile-specific victimization rate would have been for each type of crime if all modeled aspects of each quintile's demographic composition had not changed since 1975 (cf. Blinder, 1973; Oaxaca, 1973 for similar approaches used in labor economics). To do that, it is first necessary to estimate a version of the following equation, which relates the demographic characteristics of individuals (or households in the case of property crimes) to their level of victimization in that year:

$$
V^{1994}=X^{1994} \beta^{1994}+\varepsilon
$$

where $V^{1994}$ is a vector describing the number of victimizations for every individual (or household) in 1994, $X^{1994}$ is a matrix describing the demographic characteristics of every individual (or household) in 1994, and $\beta^{1994}$ is a vector of coefficients relating demographic characteristics to victimization risk. The estimate for $\beta^{1994}$ can then be applied to the observed demographic characteristics of each individual (or household) in 1975 to generate predicted values under the counterfactual scenario - estimates of what the quintile victimization rates would have been for each type of crime if each quintile's demographic composition had not changed since 1975 but the victimization equation (i.e. the relationship between demography and victimization risk) had changed in the way it actually did. Formally, that is accomplished by calculating:

$$
\hat{V}^{\text {counterfactual }}=X^{1975} \hat{\beta}^{1994}
$$

and then estimating the quintile victimization rates in the usual fashion (as described in section 3), using $\hat{V}^{\text {counterfactual }}$ rather than $V^{1975}$ to tabulate the victimization rate for each income group. The result describes the distribution of victimization that would occur if every individual in the 1975 population suffered the same risk of victimization as his or her exact demographic counterparts in 1994 did.

To estimate Eq. (1), I focused on the demographic characteristics mentioned previously using six variables: Young, Female, Married, Working, Residential Location, and Quintile. For violent crimes, where the victims are individuals, young, female, married, and working are dichotomous variables indicating whether an individual is 15-24 years old, female, married, and employed, respectively; residential location refers to dummy variables indicating whether the individual lives in an urban center, a suburb, or a rural area; and quintile describes the individual's household income, from the poorest quintile (1) to the richest (5). For burglaries and thefts, where the victims are households, Quintile and urban are defined the 
same way as for individuals, and Female is omitted (households have no gender). Married, Young, and Employed indicate whether anyone in the household is married, aged 15-24, or employed.

The most appropriate model for this analysis is a negative binomial regression of victimization on each of the independent variables, since the negative binomial technique was developed specifically for data in which the dependent variable is a number of events and the majority of observations are zeros (Greene, 1997, p. 939). ${ }^{10}$ All variables are entered as linear terms except quintile, which is entered as its natural logarithm because victimization tends to decrease nonlinearly with income. In addition to these individual terms, several interaction terms might appear to be relevant for these models, including the obvious interaction between marital status and age and the interaction between residential location and income quintile (since income affects residential choice and vice versa). As it turns out, however, few such interactions are statistically significant, and their collinearity both with each other and with the linear terms makes the coefficients on several terms unstable. In any case, these interactions do not affect the model predictions (as discussed below), so I excluded them from the final model for simplicity.

Table IV shows the coefficients of the best-fitting equations that result when Eq. (1) is estimated for each type of crime in 1994. Nearly all of the coefficients are statistically significant and have the expected effects on victimization (e.g. ceteris paribus, the young are generally victimized more than the old, the unmarried more than the married, and the poor more than the wealthy) suggesting that the models have been reasonably well-specified. For violent crimes, applying the coefficients in Table IV to the 1975 dataset (using a version of Eq. (2) to do so) yields a victimization rate of 61.9 per 1,000 residents in the poorest quintile and a rate of 45.4 per 1,000 in the richest quintile, for a 20-20 ratio of 1.36 . That finding indicates that if the demographic composition of each quintile had remained constant since 1975 while the relationship between demographic characteristics and victimization risk changed in the way that it actually did, the 20-20 ratio for violent crimes would have grown to only 1.36 instead of $1.66 ; 62 \%$ of the growth in victimization inequality would have been avoided. Similarly, under those conditions the $20-20$ ratio for theft would have grown to only 0.61 rather

\footnotetext{
${ }^{10}$ To estimate and apply the models, each record must be weighted by the number of person-years it represents (all interviews cover 6-month reporting periods, and interviews are conducted throughout the year, so each interview reports victimizations for $0-50 \%$ of a given calendar year). It is also necessary to account for the fact that due to the design of the crime surveys, some records are not statistically independent of each other. Details of these methodological issues are available from the author.
} 
Table IV. Multivariate relationships between demographic variables and victimization risks

\begin{tabular}{lccc}
\hline & \multicolumn{3}{c}{ Incidence rate ratios $^{a}$} \\
\cline { 2 - 4 } Variable & Violent crimes & Burglary & Theft \\
\hline Suburban & $0.862^{*}$ & $0.790^{*}$ & $0.809^{*}$ \\
Rural & $0.589^{*}$ & $0.577^{*}$ & $0.568^{*}$ \\
Working & $2.004^{*}$ & $1.498^{*}$ & $2.677^{*}$ \\
Work status unknown & $2.876^{*}$ & $1.684^{*}$ & $2.392^{*}$ \\
Married & $0.429^{*}$ & $0.748^{*}$ & 1.033 \\
Marital status unknown & 1.277 & 2.181 & 1.026 \\
Young & $1.888^{*}$ & $1.599^{*}$ & $1.967^{*}$ \\
Ln(quintile) & $0.775^{*}$ & $0.745^{*}$ & $1.058^{* *}$ \\
Female & $0.779^{*}$ & $\mathrm{~N} / \mathrm{A}$ & $\mathrm{N} / \mathrm{A}$ \\
\hline
\end{tabular}

Negative binomial regression predicting number of victimizations by crime type, 1994 . $* \mathrm{p}<0.01 ; * * \mathrm{p}<0.05$.

${ }^{a}$ Estimated coefficients for the binomial regression have been transformed into incidence rate ratio to facilitate interpretation. For every variable except quintile, the IRR shows the ratio (ceteris paribus) of victimization risk for those who have the relevant characteristic to the risk for those who do not. For In(quintile), it show the effect on victimization risk of a one unit change in In (quintile).

than 0.71 ( $48 \%$ of the growth avoided), and the ratio for burglary would have grown to only 1.52 rather than 1.78 (39\% for the growth avoided).

To test the robustness of these findings, I investigated alternative model specifications (including OLS regression, logistic regression, and models that included several interaction terms) as well as alternative measures of the household variables (e.g. measuring age as the number of people in the household aged 15-24, rather than as a dichotomous variable indicating whether any member of the household fell into that age range). None of these alternative specifications changed any of the predicted values for the 20-20 under the counterfactual scenario by more than $6 \%$. Quintile-specific changes in demographic composition seem to explain a large share of the trends in victimization inequality.

\section{CONCLUSIONS}

This paper has shown that the decline in crime that the United States has experienced over the past three decades has not been shared equally: The wealthy have enjoyed the benefits of this decline much more than the poor have. That finding confirms and extends the similar finding first noticed by Levitt (1999a), showing that once the effects of the redesign of the NVCS are taken into account, all crime types, not just property crimes, have become more concentrated among the poor. As of 2000 , theft victimization remains slightly more concentrated among the richest quintile than the poorest 
quintile (though the gap has closed considerably since the 1970s), but violent crime and burglary - the two most serious types of crime studied here - are much more concentrated among the poor, and the disparity has grown considerably over the past 25 years. For the most serious violent crimes, the disparity between rich and poor has become quite large. For example, in 2000 , the poorest quintile was nearly three times as likely as the richest quintile to be victimized by "serious violent crimes" as defined by the Bureau of Justice Statistics.

In sum, it is apparent that trends in the distribution of criminal victimization have reinforced other trends in social inequality, such as the trends in income and health inequality (Levy and Murnane, 1992; Pappas et al., 1993). The good news is that all groups have seen their rates of victimization fall; the rates have simply fallen much faster for the rich than for the poor. The bad news is that the gains of the poorest quintile seem fragile and relatively small; for example, their rates of violent crime victimization did not dip below 1974 levels until 1995 (and until 1998 they remained within $8 \%$ of the 1974 figure), while rates for the richest quintile have stayed below their 1974 level since 1983, and by 2000 they were down by $57 \%$. In any case, the growing concentration of victimization among the poorest quintile appears to be associated with demographic changes in each income group. Compared with the richest quintile, the poorest quintile became younger, more urban, more likely to be unmarried, and poorer-all characteristics associated with high-victimization rates-from 1975 to 1994. These changes account for a large share of the trends in victimization inequality, though one-third remains unexplained.

These findings call for three kinds of additional research encompassing descriptive, normative, and explanatory scholarship. First, to confirm the finding that victimization has truly become more concentrated among the poor, it would be useful to analyze datasets other than the NCVS. The trends described here do seem robust, particularly since the trends in inequality persist even when focusing on more serious crimes, which are less affected by peculiarities of survey design. Still, it is possible that subtle changes in survey design account for some of the apparent trends in victimization inequality. Other data sources, such as police or hospital admissions data, may offer ways to explore this possibility (cf. Levitt, 1999a, pp. 91-95). In the case of police data, detailed information about victim characteristics is rarely available, but it may be possible to geocode criminal incident data to make reasonable guesses about those characteristics (cf. Meehan and Ponder, 2001).

Second, the findings in this paper indicate a need for normative analysis to distinguish troubling inequalities from less significant inequalities. Three questions deserve special attention. First, should inequality per se should be 
a matter of concern even when all groups are becoming better off in an absolute sense? Any answer to this question will need to take account of the causes of inequality. If growing concentration of crime among the poor had anything to do with public policies, it is probably normatively significant even if the poor's victimization risk is falling, since public policy that benefited the wealthy three-and-a-half times as much as it benefited the poor would likely be inequitable (but see Rawls, 1971, pp. $60 \mathrm{ff}$. for a possible exception). On the other hand, if policy did not contribute to these trends, relative inequality may not be troubling. The fact that demographic change explains a large share of the growth in victimization inequality for the most serious crimes (i.e. violence) suggests that the latter conclusion is more appropriate, but it is important to emphasize that more than one-third of that growth remains unexplained, so it remains possible that policy played a role. A second normative question raised by this research is whether inequality is normatively significant if it is explained by demographic changes in each quintile. Again, any answer to this question will need to draw careful distinctions. On one hand, victimization inequality associated with different age distributions in each quintile may not be normatively significant since much of it will even out over the life course (cf. Daniels, 1996). If so, empirical research about victimization inequality should arguably focus on some measure of an individual's lifetime risk of victimization, asking whether lifetime risk has become more unequal across economic groups. On the other hand, victimization inequality associated with differences in marital status composition across quintiles may be more troubling, since the breakup of the family in lower income groups is arguably not something that will even out over the life course or something that has been freely chosen (Wilson, 1987). Finally, Levitt (1999a) suggests a third normative question relevant to this research: How should the costs of self-protective behavior be weighed against the costs of victimization per se in calculating the extra burden that crime places on the poor? Levitt argues that "any measure of the burden of crime should incorporate not only the costs of those victimized, but also the investment made to avoid victimization" (1999a, p. 88). The position is a plausible one, but it is important to note that literature about other forms of stratification has not generally attended to indirect burdens of this kind. (For example, students of income inequality focus on income without recognizing that lower income may sometimes be compensated by more leisure, and students of health inequality focus on health outcomes without recognizing that poor health may be "compensated" by lower expenditures on health care or a more indulgent lifestyle.) In any case, Levitt's position suggests a view of distributive justice that focuses on the distribution of overall well-being, of which victimization risk and expenditures on self-protection are inter- 
changeable components. An alternative view of distributive justice focuses on the distribution of specific goods that have special importance to all individuals (e.g. Rawls, 1971, pp. 62, 90 ff.); neighborhood safety may have that kind of intrinsic importance. The choice between these two views, and the proper interpretation of each as applied to the problem of victimization inequality, is a complex normative issue that deserves further analysis.

In sum, the key point is that there is a need for further normative analysis that can help to clarify the forms of inequality that should be most troubling (such as those that do not even out over the life course, those that do not stem from free choices, and those that persist despite the use of appropriate self-protective measures) in order to guide empirical analysis to the most significant problems. Just as explanatory research needs to be guided by causal theories that identify potentially important independent variables, descriptive research needs to be guided by normative theories that identify potentially important dependent variables (Zald, 1991). This paper already draws from one theory of that kind - the idea that inequality in the distribution of a social burden is significant when it exacerbates inequalities of other origins (Walzer, 1973; Barr and Pease, 1990; Miller, 1995). But future research should try to supplement that basic idea, perhaps in the ways the previous paragraph has suggested, in order to develop a more nuanced normative theory relevant to the distribution of criminal victimization.

Finally, there is a need to develop and test causal theories that can explain the growth in victimization inequality. This paper has shown that one simple explanation is consistent with recent U.S. trends: Demographic change has exacerbated victimization inequality by concentrating high-risk groups in the lower economic strata. Nevertheless, although that explanation can account for two-thirds of the growth in victimization inequality for violent crimes from 1975 to 1994 and a large share of the trends for burglary and theft, it is not an especially deep explanation sociologically (much like the models that explain changes in aggregate crime rates with reference to changes in the population's age structure). Future work should try to enrich this theory by investigating why demographic change is associated with changes in victimization inequality - i.e. by investigating the variables that mediate that relationship, such as self-protective behavior and contact with offenders.

In any case, successful explanations for the trends in victimization inequality will need to be consistent with the basic facts about those trends that this paper has uncovered: That the concentration of victimization among the poor began to grow in the early 1980s, that this growth has been concentrated in nonstranger crimes rather than stranger crimes, and that it has been associated with quintile-specific changes in demographic composition. Lifestyle and routine activity theories offer one 
possibility. Those theories suggest that a group's victimization rate will be influenced by the lifestyle and daily routines of its members (Meier and Miethe, 1993). Many of the demographic patterns noted here are consistent with this view: Groups that have traditionally been identified with high-risk routine activities (such as the young and the unmarried, who spend more time in public and come into contact with motivated offenders more often) have become more concentrated in lower income groups. That shift suggests that on average, the lifestyles and routines activities of lower income groups may have changed in ways that are associated with higher rates of victimization. The NCVS did not measure routine activities directly until 1992, so it is not possible to determine whether routine activities have changed in each quintile since the 1970s. Nevertheless, cross-sectional research (e.g., research across U.S. regions or between the U.S. and other nations) and more limited longitudinal research since 1992 could shed some light on the ability of lifestyle and routine activity theory to explain variation in victimization inequality. Perhaps the most interesting lifestyle-related explanation for the trends in victimization inequality is one that views those trends as intimately bound up with broader patterns of social stratification, which may have increasingly insulated the rich from contact with potential offenders - e.g. via greater withdrawal of the rich into safe, class-segregated neighborhoods and work environments (cf. Hindelang, et al., 1978) or via greater stratification of social networks by income. The high levels and rates of growth of inequality among intimate and acquaintance violence suggest that the latter possibility may be especially important.

Another possible explanation for the growth in victimization inequality for violent crimes is suggested by its timing and by its concentration in nonstranger crimes: Tougher criminal justice policy could have fueled victimization inequality because its deterrent value varies with the economic status of the potential offender, and therefore in some cases with the economic status of the potential victim. As John Braithwaite and others have argued, those who have a strong stake in conformity are more likely to be deterred by formal criminal sanctions than those who have a weaker stake in conformity (Braithwaite, 1989; Sherman and Smith, 1992). This idea is particularly important in the context of the United States during the late twentieth century, which markedly increased its use of the criminal sanction by incarcerating more offenders for longer periods of time (beginning particularly in the early 1980s, when victimization inequality also began to grow). If Braithwaite is right, a policy change like that may deter wealthier offenders more than poorer offenders, since correlates of economic status (like lack of employment and low educational or occupational aspirations) are associated with a 
low stake in conformity (Braithwaite, 1989). Such growing concentration of criminal offending in lower-income groups would cause growing concentration of victimization there for certain types of crime-namely, crimes where victims and offenders tend to come from the same economic class (as in the case of intimate and acquaintance violence, much of which is intra-class by definition). If there is any truth to this hypothesis, it could have important policy implications. Many proponents of tough criminal justice policies have defended them partly on the grounds that they protect the disadvantaged, who are victimized by crime more than anyone else (e.g. DiIulio, 1989). But if tough crime policy produces inegalitarian results, it is at best inefficient and at worst counterproductive from that perspective.

This particular theory about how criminal justice policy might influence victimization inequality is of course highly speculative. I mention it here only to offer an example of an important possibility that deserves theoretical and empirical attention: that public policy may play an important role in shaping the distribution of victimization. Whether or not this particular theory has any validity, the findings of this paper indicate a need for policy research with that kind of distributional focus-research that explores not just whether specific policy interventions reduce the overall level of victimization but also how the benefits of those interventions are distributed. Such research is particularly important today because even more than in the past, crime has increasingly become a distinctive problem of the poor rather than a problem for society in general.

\section{ACKNOWLEDGMENTS}

I would like to thank Rebecca Blank, Tony Chen, John DiNardo, Jude Hays, Steve Levitt, Frank Levy, and the anonymous reviewers at The Journal of Quantitative Criminology for very helpful comments and discussion about this paper.

\section{REFERENCES}

Barr, R., and Pease, K. (1990). Crime placement, displacement, and deflection. In Tonry, M., and Morris, N. (eds.), Crime and Justice, Vol. 12, pp. 277-318.

Blinder, A. (1973). Wage discrimination: Reduced form and structural estimates. J. Human Resours. 8: 436-455.

Braithwaite, J. (1989). Crime, Shame, and Reintegration. Cambridge Univ. Press, New York.

Cohen, L.E., and Felson, M. (1979). Social change and crime rate trends: A routine activity approach. Am. Sociol. Rev. 44: 588-608. 
Daniels, N. (1996). The prudential life-span account of justice across generations. In Daniels, N. (ed.), Justice and Justification, Cambridge Univ. Press, New York, pp. 257-283. DiIulio, J. (1989). The impact of inner-city crime. Public Interest 96: 28-46.

Felson, M. (1987). Routine activities and crime prevention in the developing metropolis. Criminology 25: 911-91.

Greene, W. H. (1997). Econometric Analysis, 3d edn. Prentice Hall, Upple Saddle River, NJ.

Hart, T., and Rennison, C. (2003). Reporting Crime to the Police, 1992-2000. Bureau of Justice Statistics Special Report, no. NCJ-195710.

Hindelang, M.S., Gottfredson, M., and Garofalo, J. (1978). Victims of Personal Crime. Ballinger, Cambridge, Mass.

Johnston, J., and DiNardo, J. (1997). Econometric Methods, 4th edn. McGraw-Hill, New York.

Kakwani, N., Wagstaff, A., and van Doorslaer, E. (1997). Socioeconomic inequalities in health: Measurement, computation, and statistical inference. J. Econometrics 77: 87-103.

Kindermann, C., Lynch, J., and Cantor, D. (1997). Effects of the Redesign on Victimization Estimates. Bureau of Justice Statistics Technical Report Series, no. NCJ-164381.

Lauritsen, J., and White, N. (2001). Putting violence in its place: The influence of race, ethnicity, gender, and place on the risk for violence. Criminol. Public Pol. 1: 37-59.

Lerman, R. (1997). Reassessing trends in U.S. earnings inequality. Monthly Labor Rev. 120: $17-25$.

Levitt, S. (1999a). The changing relationship between income and crime victimization. Fed. Reserve Bank of New York Econ. Policy Rev. 5: 87-98.

Levitt, S. (1999b). The limited role of changing age structure in explaining aggregate crime rates. Criminology 37: 581-597.

Levy, F., and Murnane, R. J. (1992). U.S. earnings levels and earnings inequality: A review of recent trends and proposed explanations. J. Econ. Lit. 30: 1333-1381.

Meehan, A.J., and Ponder, M. (2001). Race, Place and Racial Profiling: Using Mobile Data Terminal Data to Analyze Racial Profiling. Paper presented at the 41st meeting of the American Society of Criminology, Atlanta, Georgia.

Meier, R. F., and Miethe, T. D. (1993). Understanding theories of criminal victimization. In Tonry, M. (ed.), Crime and Justice, Vol. 17, pp. 459-499.

Miller, D. (1995). Complex equality. In Miller, D. and Walzer, M. (eds.), Pluralism, Justice, and Equality, Oxford Univ. Press, New York, pp. 197-225.

Oaxaca, R. (1973). Male-female wage differentials in urban labor markets. Int. Econ. Rev. 14: 693-709.

Pappas, G., Queen, S., Hadden, W., and Fisher, G. (1993). Increasing disparity in mortality between socioeconomic groups in the united states, 1960 and 1986. New England J. Med. 329: 103-109.

Perkins, C., and Klaus, P. (1996). Criminal Victimization 1994, Bureau of Justice Statistics Special Report Series, no. NCJ-163069.

Rand, M., Lynch, J., and Cantor, D. (1997). Criminal Victimization, 1973-1995, Bureau of Justice Statistics Bulletin, no. NCJ-158022.

Rawls, J. (1971). A Theory of Justice. Harvard Univ. Press, Cambridge, Mass.

Rennison, C. (2001). Criminal Victimization 2000, Bureau of Justice Statistics Report, no. NCJ-187007.

Sampson, R. J., and Lauritsen, J.L. (1997). Racial and ethnic disparities in crime and justice in the United States. In Tonry, M. (ed.), Crime and Justice, Vol. 21, pp. 311-374.

Sherman, L., and Smith, D. (with Schmidt, J., and Rogan, D.) (1992). Crime, punishment, and stake in conformity. Am. Sociol. Rev. 57: 680-690.

Trickett, A., Ellingworth, D., Hope, T., and Pease, K. (1995). Crime victimization in the eighties: Changes in area and regional inequality. Br. J. Criminol. 35: 343-359. 
U.S. Census Bureau (1974-2000). March Current Population Survey, various years. USGPO, Washington, DC.

U.S. Dept. of Justice, Bureau of Justice Statistics (1974-2000). Criminal Victimization in the United States, various years. USGPO, Washington, DC.

U.S. Dept. of Justice, Bureau of Justice Statistics (1998-1999). National Crime Surveys: National Sample, 1975-1976 and 1994-1995 [Computer files]. Conducted by U.S. Dept. of Commerce, Bureau of the Census. 6th ICPSR ed. Ann Arbor, MI: Inter-university Consortium for Political and Social Research [producer and distributor].

Wagstaff, A., van Doorslaer, E., and Paci, P. (1989). Equity in the finance and delivery of health care. Oxford Rev. Econ. Policy 5: 89-112.

Walzer, M. (1973). In defense of equality. Dissent 20: 399-408.

Wilson, W.J. (1987). The Truly Disadvantaged. University of Chicago Press, Chicago.

Zald, M. (1991). Sociology as a discipline: Quasi-science, quasi-humanities. Am. Sociol. 22: 165187.

Zimring, F., and Hawkins, G. (1997). Crime is Not the Problem: Lethal Violence in America. Oxford Univ. Press, New York. 